\title{
Biodiesel Process Simulation: 2. Process Synthesis and Design Case Study
}

\author{
F. RODRIGUES ${ }^{1}$ e A. J. de ASSIS $^{1}$ \\ ${ }^{1}$ Universidade Federal de Uberlândia, Faculdade de Engenharia Química, Núcleo de Modelagem, \\ Controle e Otimização de Processos \\ E-mail for contact: fabricio@equi.ufu.br, ajassis@feq.ufu.br
}

\begin{abstract}
Based on reliable property values, a framework for biodiesel process synthesis, design and simulation was created. To assess the capabilities of this framework, the biodiesel production from degummed oil and ethanol was taken as a process design case study. The process is synthesized based on a systematic methodology that uses knowledge and the thermodynamics insight theory to generate and evaluate process alternatives. A preliminary process design is proposed and simulated on COCO (CAPE-OPEN-to-CAPEOPEN) process simulator confirming the contribution of this work as a tool for the application of process and product design techniques.
\end{abstract}

\section{INTRODUCTION}

Biodiesel fuel has countless advantages in comparison to fossil fuels (Hill et al., 2006), nonetheless there are also many hurdles for its production and consumption. According to Ma and Hanna (1999), the cost of biodiesel is the main hurdle to its commercialization. Siirola (1996) demonstrated the importance of process synthesis from the industrial point of view, "typical energy savings of $50 \%$ and net present cost reductions of 35\% in industrial practice have been achieved using systematic process synthesis methodologies" and Harmsen (2004) gives several examples of successful industrial applications and best practices of process synthesis methods and tools. However, the application of these methods and tools often requires knowledge of reliable physicochemical property values and that these properties and their estimation methods are computationally available (to be used by process synthesis and design tools such as simulators). This hurdle was partially ${ }^{1}$ overcome in a precedent article (Rodrigues and Assis, submitted for publication).

In this work, we focus on the analysis and assessment of a design case studies dealing with the alkali-catalyzed transesterification of degummed soybean oil with ethanol. In Figure 1 it is schematized the set of reactions that form the transesterification. In regular conditions (e.g. subcritical), the reaction must be catalyzed (usually an alkali catalyst is used such as $\mathrm{NaOH}$ or $\mathrm{KOH}$ ) in order to achieve good conversions.

\footnotetext{
${ }^{1}$ The work addresses most required properties for biodiesel simulation except activity coefficient (VLE calculations).
} 


$$
\begin{aligned}
& \text { Triglyceride }+\mathrm{CH}_{3} \mathrm{CH}_{2} \mathrm{OH} \rightleftharpoons \text { Diglyceride }+ \text { Ethyl Ester } \\
& \text { Diglyceride }+\mathrm{CH}_{3} \mathrm{CH}_{2} \mathrm{OH} \rightleftharpoons \text { Monoglyceride }+ \text { Ethyl Ester } \\
& \text { Monoglyceride }+\mathrm{CH}_{3} \mathrm{CH}_{2} \mathrm{OH} \rightleftharpoons \text { Glycerol }+ \text { Ethyl Ester }
\end{aligned}
$$

Figure 1 - The transesterification reactions of vegetable oil with ethanol forming ethyl ester (biodiesel).

The raw materials were chosen based on some important characteristics. Ethanol is a renewable energy source with less environmental effects than methanol and is widely available in Brazil. Degummed soybean oil is an inedible partially processed oil that has a reduced price. It has the same main constituents of refined soybean oil except that it was not neutralized, clarified and deodorized and has the presence of some minor fatty acids, antioxidants and pigments. In Table 1, the fatty acids composition of degummed oil is presented.

Table 1 - Degummed oil fatty acid composition (Rade, 2014)

\begin{tabular}{|c|c|c|}
\hline \multicolumn{2}{|c|}{ Fatty Acid } & Composition (wt\%) \\
\hline C16:0 & Palmitic acid & 9.95 \\
\hline C18:0 & Stearic acid & 3.92 \\
\hline C18:1 & Oleic acid & 27.11 \\
\hline C18:2 & Linoleic acid & 52.98 \\
\hline C18:3 & Linolenic acid & 6.03 \\
\hline
\end{tabular}

\section{PROCESS SYNTHESIS AND DESIGN CASE STUDY}

The objective of this section is to generate a conceptual process design for the production of biodiesel from degummed oil and ethanol. The generation of alternatives or process synthesis, is the procedure by which we find good design alternatives without an exhaustive search. According to Westerberg (2004), process synthesis involves many important aspects such as mathematical programming/optimization, heuristics and innovation; and another number of important concerns such as economic, safety, control and sustainability. Addressing all the aspects and concerns of process synthesis and design generates an ill-posed problem definition as classified in computer science by Simon (1969). Decomposition approaches are a way to transform the ill-posed problem definition in a well-posed problem by breaking down the problem definition in a finite number of sub-problems. 


\section{9 a 22 de outubro de 2014 \\ Florianópolis/SC}

Biegler et al. (1998) proposes that the synthesis step can be divided in four steps: (1) gathering information, (2) representing alternatives, (3) criteria for assessing preliminary designs and (4) generating and searching among alternatives. Following this structure, the gathering information step covers the reactions and its kinetics as well as recommended operation conditions found in open literature. The alternatives are represented (step 2) in three different levels of aggregation presented in the next sections. The third and fourth steps are merged in the application of the thermodynamic insights theory developed by Jaksland et al. (1995). The thermodynamic insights theory employs physicochemical properties and their relationships to separation techniques for design and synthesis of separation processes. Pure compound and mixture property ratios are related to separation techniques based on empiricism, for example if the boiling point ratio between two compounds is higher than 1.4 distillation is probably feasible, if it is between 1.4 and 1.2 distillation is feasible and if it is less than 1.1 distillation is probably unfeasible.

\subsection{Gathering Information}

Most of the biodiesel is currently produced through a transesterification reaction using an alkali catalyst (Gerpen, 2005). Typical reaction conditions are 6:1 molar ratio of ethanol to oil, $70^{\circ} \mathrm{C}$ and atmospheric pressure (Likozar and Levec, 2014). However, if the feed oil contains a large amount of free fatty acids (FFA) the reaction is compromised due to soap formation that inhibits the separation of the ester from glycerin and reduce the ester conversion rate (Carnicki and Gerpen, 2001). Degummed oil has around $8 \mathrm{wt} \%$ of FFA and therefore the transesterification reaction faces several problems when carried out only using an alkali catalyst as pointed out by Rade (2014).

Pretreatment-step: Carnicki and Gerpen (2001) developed a multi-step technique to reduce the FFA level of high FFA feedstock to less than 1\% FFA using an acid-catalyzed (usually $\mathrm{H}_{2} \mathrm{SO}_{4}$ ) pretreatment. The process was shown to be successful for a synthetic mixture of soybean oil containing with $20 \%$ of palmitic acid. This technique requires $5 \mathrm{wt} \%$ of $\mathrm{H}_{2} \mathrm{SO}_{4}$ in a first reactor with a 10:1 molar ratio of ethanol to FFA at $60{ }^{\circ} \mathrm{C}$ followed by the removal of ethanol and water, then the effluent mixture is reacted again using a $6: 1$ molar ratio of ethanol to FFA at $60{ }^{\circ} \mathrm{C}$ and achieves almost complete conversion of FFA.

Alkali-catalyzed reaction-step: As the pretreatment step is able to reduce the free fatty acids concentration to an acceptable value, the conventional alkali-catalyzed transesterification reaction can be used. Likozar and Levec (2014) have published kinetic parameters for all the reactions involved, typical reaction conditions are $6: 1$ molar ratio of ethanol to oil, $70^{\circ} \mathrm{C}$ and atmospheric pressure.

At this point, the basic structure of the flowsheet is developed as represented in Figure 1. The next step is to synthesize the separation processes (1), (2) and (3) also shown in Figure 1, for that the thermodynamic insights theory is applied. 


\subsection{Synthesis of Separation Process based on Thermodynamic Insights}

The method consists of six main steps dealing with mixture analysis, computation of binary ratio matrix, separation process identification, screening of alternatives, initial estimates of split factors and choice of the first separation task. According to Figure 1, there are three streams to be separated, the effluents from pretreatments 1 and 2 (the stream names are abbreviated to EPT1 and EPT2) that will lead to similar separation process and the effluent from the alkali-catalyzed reaction (EAR).

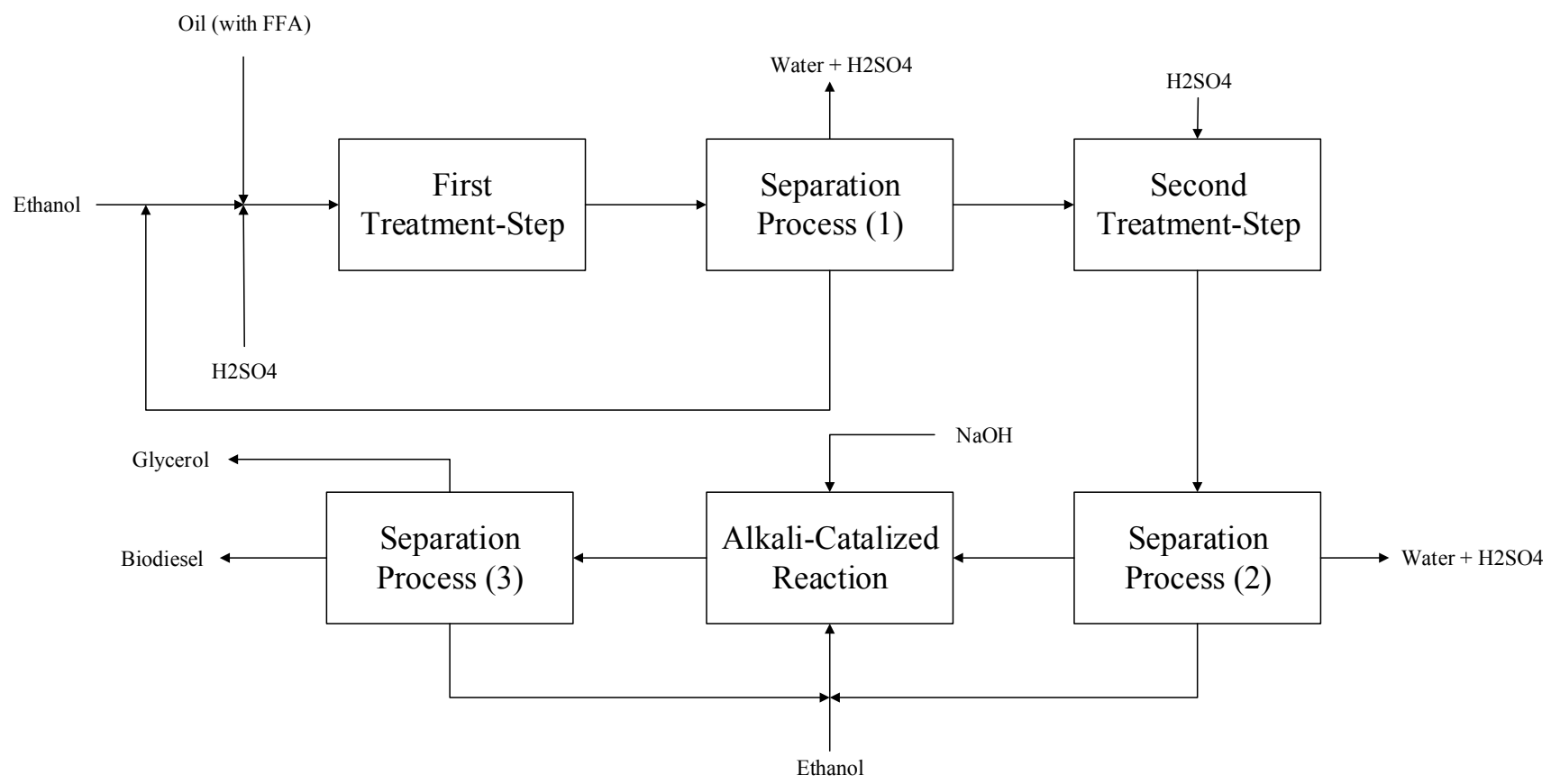

Figure 1 - Flowsheet developed at the end of the gathering information step shown in two levels of agregations (total flowsheet and task-based flowsheet).

The application of the thermodynamic insights method is divided in two cases one regarding streams EPT1 and EPT2, and the second regarding stream EAR. The first step applies in the same way for both streams, the mixture is nonideal with only a very reduced group of VLE experimental data available. Both streams are in the liquid phase at atmospheric pressure, EPT1 and EPT2 are at $60^{\circ} \mathrm{C}$ and EAR is at $60^{\circ} \mathrm{C}$. For the calculation of the binary ratio matrix, simplifications are made by ignoring compounds present in reduced amounts (less than $1 \%$ ), still very large matrices are generated. The binary ratio matrix for streams EPT1 and EPT2 have six binary pairs and the binary ratio matrix for stream EAR has ten binary pairs, the number of binary pairs represents the number of rows and both matrices have 12 columns (12 properties are analyzed). The third step of the methodology is separation process identification, the methodology sets three intervals (very feasible, feasible and infeasible separations) for each group of property ratios that are related to a separation technique (a simple comparison of the property ratios of each binary pair with prefixed property ratio values) identifying 
the separation techniques that are infeasible. The other steps of the methodology are more straightforward, and we can proceed to process simulation on $\mathrm{COCO}^{2}$. The complete flowsheet is showing the separation process synthesized is shown in Figure 2. The process has many recycles that hinder the first-sight understanding of the process, nonetheless the flowsheet can be divided in three parts that make easier to understand the process (1) fatty acids removal, (2) transesterification and (3) biodiesel purification.

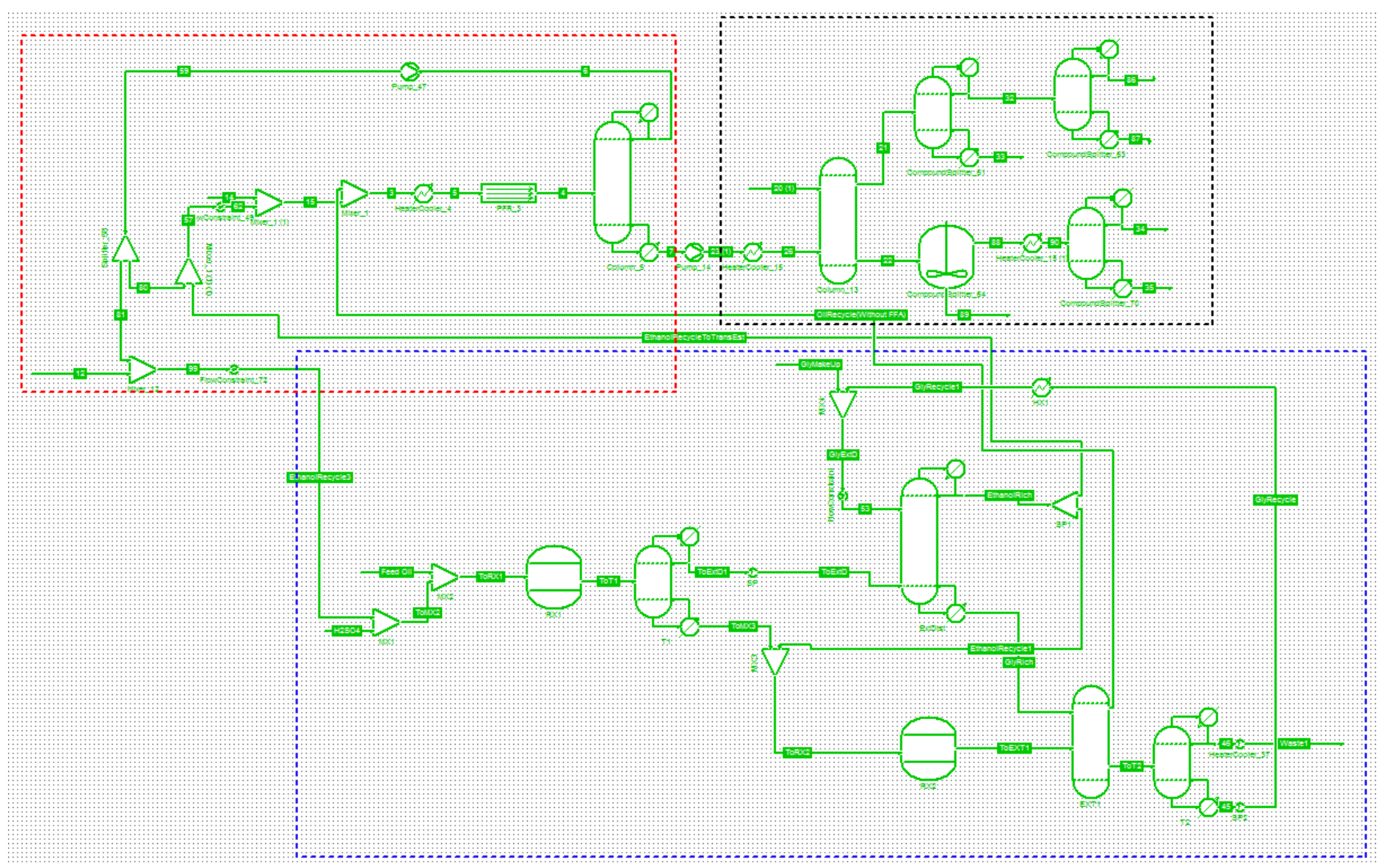

Figure 2 - Process flowsheet for the production of biodiesel from degummed oil, the units inside each rectangle represents a division of the process

(Blue: FFA removal, Red: Transesterification, Black: Biodiesel purification).

Fatty acids removal: The bottom part of the flowsheet performs the esterification of the FFA following the two-step technique proposed by Carnicki and Gerpen (2001) and it starts by mixing the catalyst with an ethanol recycle from the transesterification process, the resulting stream is fed to the reactor together with the degummed oil for the first acid-catalyzed esterification. The effluent is split in a vacuum-distillation column with four stages, the top stream is mainly composed by ethanol and water that are sent to an extractive distillation column (water and ethanol form an azeotrope) that uses glycerol

\footnotetext{
${ }^{2}$ For activity coefficient and fugacity calculations, the original UNIFAC and the ideal gas law were used, respectively.
} 
as the solvent (Seader et al., 2010). The bottom stream contains the fatty compounds and catalyst that are fed to the second esterification-step. The second esterification effluent is treated in a five stages extractor using the bottom stream from the extractive distillation that is rich in glycerol, the top stream does not contain water nor catalyst and is sent to transesterification. The bottom stream from the extractor is fed to an atmospheric pressure distillation column with six stages, the bottom is pure glycerol that is recycled back to the extractive distillation after been mixed with a makeup stream.

Transesterification: The starting point of the transesterification part is the ethanol recycle from the FFA removal that is mixed with part of the ethanol recovered after the transesterification. The resulting stream is mixed with the alkali catalyst and are fed to a $8 \mathrm{~m}^{3}$ plug-flow reactor with the feed oil (FFA-free). The PFR effluent is composed by ethanol, glycerol, water and the produced ethyl esters, the high composition of ethanol permits a sharp separation of ethanol as the top product from a fivestages vacuum-distillation column; the bottom product contains all the other compounds and these are sent to the Biodiesel purification part of the flowsheet.

Biodiesel purification: The bottom stream from the ethanol recovery column contains ethyl esters, glycerol, ethanol and catalyst $(\mathrm{NaOH})$; this stream is split in a five stages extractor using water as the entrainer (Seader et al., 2001). The top stream is mostly composed of ethyl esters, unreacted fatty compounds, ethanol and water, these are separated in two distillation columns. In the first column the fatty compounds are obtained in the bottom and in the second column, a waste stream composed by ethanol and water and the main product stream containing high purity ethyl esters (biodiesel) are obtained in the top and bottom, respectively.

The design is able to produce $355 \mathrm{~kg} / \mathrm{hr}$ of biodiesel from $626 \mathrm{~kg} / \mathrm{hr}$ of degummed oil. The composition and properties of the biodiesel produced are shown in Table 2 and 3, respectively.

Table 2 - Composition of the biodiesel produced

\begin{tabular}{|c|c|c|}
\hline \multicolumn{2}{|c|}{ Ethyl Ester } & Composition (mol \%) \\
\hline C16:0 & Ethyl palmitate & 7 \\
\hline C18:0 & Ethyl stearate & 2.6 \\
\hline C18:1 & Ethyl oleate & 27.02 \\
\hline C18:2 & Ethyl Linoleate & 57.38 \\
\hline C18:3 & Ethyl Linolenate & 6 \\
\hline
\end{tabular}


Table 3 - Some properties of the biodiesel produced

\begin{tabular}{|l|l|}
\hline \multicolumn{1}{|c|}{ Property } & \multicolumn{1}{c|}{ Value } \\
\hline Density $\left(25^{\circ} \mathrm{C}\right)$ & $640.624 \mathrm{~kg} / \mathrm{m}^{3}$ \\
\hline Cetane Number & \\
\hline Viscosity $\left(25^{\circ} \mathrm{C}\right)$ & 47.9 \\
\hline Flash Point & \\
\hline Cloud Point $^{3}$ & 5293.843 Pa.s \\
\hline Pour Point $^{3}$ & $471.725 \mathrm{~K}$ \\
\hline Cloud Flow Plugging Point $^{3}$ & $288.550 \mathrm{~K}$ \\
\hline
\end{tabular}

\section{CONCLUSIONS}

Clearly, the design presented must be further analyzed in many other aspects (such as heat integration, optimization, sustainability, safety, control and the recent trend of process intensification) before achieving the maturity for industrial implementation. However, the design proposed is a long step towards an efficient biodiesel production process. It is also important to note the very important role that properties play during process design, especially conceptual process design. The framework created in the precedent work (Rodrigues and Assis, submitted for publication) showed its capabilities by enabling biodiesel process synthesis, design and simulation. Furthermore, all the analysis was conducted using free software such as COCO and the .NET framework used to develop BioPES.

\section{REFERENCES}

BIEGLER, L. T.; GROSSMANN, I. E.; WESTERBERG, A. W. Systematic Methods of Chemical Process Design. New Jersey: Prentice Hall, 1998.

CANAKCI, M.; GERPEN, J. V. Biodiesel Production from Oils and Fats with High Free Fatty Acids. Transactions of the American Society of Agricultural Engineers, v. 44, n. 6, p. 1429-1436, 2001.

GERPEN, J. V. Biodiesel processing and production. Fuel Processing and Technology, v. 86, p. 10971107, 2005.

HILL, J.; NELSON, E.; TILMAN, D.; POLASKY, S.; TIFFANY, D. Environmental, economic, and

${ }^{3}$ Estimated by Klopfenstein (1982) method.

${ }^{4}$ Estimated by Su et al. (2011) method. 
energetic costs and benefits of biodiesel and ethanol biofuels. Proceedings of the National Academy of Sciences of the United States of America, v. 103, n. 30, p. 11206-11210, 2006.

JAKSLAND, C. A.; GANI, R.; LIEN, K. M. Separation Process Design and Synthesis based on Thermodynamics Insights. Chemical Engineering Science, v. 50, n. 3, p. 511-530, 1995.

KLOPEFENSTEIN, W. E. Estimation of Cetane Index for Esters of Fatty Acids. Journal of the American Oil Chemists Society, 1982, v. 59, n. 12, p. 531-533.

LIKOZAR, B.; LEVEC, J. Transesterification of canola, palm, peanut, soybean and sunflower oil with methanol, ethanol, isopropanol, butanol and tert-butanol to biodiesel: Modelling of chemical equilibrium, reaction kinetics and mass transfer based on fatty acid composition. Applied Energy, v. 123, p. 108-120, 2014.

RADE, L. L. Produção contínua não catalítica de biodiesel a partir de óleo de soja degomado em álcool supercrítico. Faculdade de Engenharia Química, Universidade Federal de Uberlândia. Tese de Mestrado. Uberlândia. 2014.

SEADER, J. D.; HENLEY, E. J.; ROPER, D. K. Separation Process Principles. New York: Wiley \& Sons, 2010.

SIIROLA, J. J. Industrial Applications of Chemical Process Synthesis. Advances in Chemical Engineering, v. 23, p. 1-62, 1996.

SIIROLA, J. J. Foreword. In: BIEGLER, L. T.; GROSSMANN, I.; WESTERBERG, A. W. Systematic Methods for Chemical Process Design. New Jersey: Prentice Hall, 1998. p. xvii-xviii.

SIMON, H. A. Science of the Artificial. Cambridge: MIT Press, 1969.

SU, Y.; LIU, Y. A.; TOVAR, C. A. D.; GANI, R. Selection of Prediction Methods for Thermophysical Properties for Process Modelling and Product Design of Biodiesel Manufacturing. Industrial \& Engineering Design, v. 50, p. 6809-6836, 2011.

WESTERBERG, A. W. A retrospective on design and process synthesis. Computers and Chemical Engineering, v. 28, p. 447-458, 2004.

\section{ACKNOWLEDGEMENTS}

The authors would like to thank the Brazilian National Council for Scientific and Technological Development for scholarship and the Research Foundation of the State of Minas Gerais (FAPEMIG) for funding this work. 